\title{
Filsafat Nggusu Waru dalam Tradisi Lisan Bima dan Relevansinya dengan Ciri Kepemimpinan Modern
}

\author{
Dr. Ahmad Badrun, M.Hum \\ FKIP Universitas Mataram
}

\begin{abstract}
Abstrak
Dalam tulisan ini dibahas relevansi isi filsafat Nggusu Waru dengan ciri kepemimpinan modern dan penyebab masyarakat Bima melupakan filsafat itu. Pembahasan ini dilakukan dengan metode semiotik. Hasil kajian menunjukkan bahwa 8 butir filsafat Nggusu Waru mempunyai nilai yang sama dengan ciri kepemimpinan modern, yaitu (1) matoqa đi Ruma labo Rasu (yang taat kepada Allah dan Rasul) adalah sama dengan percaya kepada Tuhan yang Mahaesa, (2) maloa ro pade 'yang pandai dan cerdas' adalah sama dengan berwawasan luas, (3) mantiri nggahi kalampa 'yang jujur dalam melaksanakan tugas' adalah sama dengan kejujuran, (4) mapoda nggahi paresa 'yang mampu menegakkan kebenaran' adalah sama dengan adil, (5) mambani ro disa 'yang bertanggung jawab dan berani' adalah sama dengan berani menanggung risiko, (6) matenggo ro wale 'sehat jasmani dan rohani serta kuat' adalah sama dengan sehat jasmani dan rohani, (7) mapisa ro guna 'berwibawa dan sakti' adalah sama dengan berwibawa atau berpengaruh, dan (8) londo dou taho 'keturunan orang baik-baik' adalah sama dengan bermoral baik. Filsafat itu tidak lagi populer karena masyarakat Bima kurang apresiatif terhadap tradisi lisannya.
\end{abstract}

\section{Pendahuluan}

Ada semacam anggapan bahwa sesuatu yang bersifat lisan kurang bernilai se-hingga keberadaan hasil budaya lisan atau tradisi lisan sering diabaikan. Orang-orang modern cenderung memilih acuan yang bersumber dari buku atau bahan cetakan. Kecenderungan seperti itu tidak bisa dipungkiri karena kita hidup dalam budaya tulis atau aksara yang menuntut segala sesuatu itu harus jelas acuannya dan acuan itu harus dapat dilacak. Lagi pula, orang modern mempunyai kecenderungan psikologis untuk selalu mencari yang lebih baru. 
Hadirnya budaya tulis telah mengubah pandangan kita atas tradisi lisan. Tradisi lisan yang dulu sebagai penampung aktivitas masyarakat lisan, sekarang hanya menjadi pelengkap. Keberadaan (bertahannya) tradisi lisan di dunia banyak bergantung pada sikap bangsa sebagai pemiliknya. Sebagian bangsa ada yang mempertahankan dan mengembangkan tradisi lisan mereka sebagai identitas. Orang Jepang memelihara hasil tradisi lisannya dengan baik, misalnya, kimono dan karate. Orang Cina juga mempertahankan olah raga kungfunya dengan baik dan bahkan mereka menyebarkannya ke seluruh penjuru dunia.

Bangsa Indonesia memiliki tradisi lisan yang beragam sesuai dengan jumlah etnik. Sebagian besar etnik di Indonesia, pada umumnya melakukan revitalisasi tradisi lisannya, misalnya Sasak, Nias, dan Bali. Revitalisasi itu tidak dapat dilepaskan dari program pariwisata karena produk tradisi lisan dianggap sebagai salah satu daya tarik bagi wisatawan yang bosan dengan kehidupan modern di negerinya. Etnik yang memiliki objek pariwisata yang bagus sangat beruntung dan sekaligus mereka dapat merevitalisasi tradisi lisan. Oleh sebab itu, dapat dikatakan bahwa daerah atau etnik yang maju pariwisatanya, tradisi lisannya akan tetap hidup.

Di NTB, selain etnik Sasak, ada dua etnik lagi yang memiliki tradisi lisan yang cukup kaya, yaitu Sumbawa dan Bima. Tradisi lisan kedua etnik itu belum direvitalisasi seperti halnya tradisi lisan Sasak. Hal itu terjadi karena tidak didukung oleh objek pariwisata yang memadai seperti di pulau Lombok. Akibatnya, tradisi lisan kedua etnik itu kurang begitu dikenal. Fenomena itu perlu disiasati agar keberadaan tradisi lisan, bukan hanya menjadi bagian sejarah, melainkan juga harus menjadi aktivitas sehari-hari masyarakat pemiliknya. Artinya, masyarakat pemilik 
harus memberi makna terhadap tradisi lisannya sehingga dapat dikenal oleh masyarakat lain.

Dalam masyarakat etnik Bima, ada satu tradisi lisan (selain patu), yaitu Filsafat Nggusu Waru (selanjutnya disingkat FNGW) atau yang disebut Nggusu Waru. Filsafat itu berkaitan dengan masalah kepemimpinan, seperti halnya filsafat Jawa Inggarso sung tulodo, ing madya mangun karso, tut wuri handayani. Filsafat Jawa itu menggambarkan bagaimana cara memimpin atau bagaimana perilaku pemimpin terhadap orang yang dipimpin, sedangkan FNGW menggambarkan ciri pemimpin. Namun, patut dihargai, filsafat Jawa itu telah diangkat menjadi filsafat kepemimpinan nasional yang dikenal dari Sabang sampai Merauke.

FNGW mempunyai nilai yang relevan dengan kepemimpinan modern, khususnya dalam hal ciri pemimpin. Namun, ciri-ciri pemimpin itu tidak dipublikasikan sehingga jarang masyarakat etnik Bima yang mengetahuinya. Kalau pun ada publikasi, hanya orang tertentu yang mau melakukannya. Akibatnya, filsafat itu menjadi terasing dari masyarakat etnik Bima. Keterasingan itu perlu dilacak penyebabnya sehingga di masa mendatang FNGW dapat menjadi acuan dalam kehidupan bermasyarakat etnik Bima.

Dalam tulisan ini akan dibahas relevansi FNGW dengan ciri kepemimpinan modern dan faktor penyebab masyarakat etnik Bima melupakan filsafat itu. Pembahasan ini dilakukan dengan metode semiotik konotatif Roland Barthes yang terkandung dalam buku Mythologies 1981. Titik perhatian metode itu adalah makna denotasi dan konotasi tanda. FNGW yang dikaji adalah versi I.M. Saleh dalam buku "Sekitar Kerajaan Dompu" (stensilan) yang diterbitkan oleh Pemda Kabupaten Dompu, tahun 1985. Sebelum buku itu diperoleh, penulis 
pernah mewawancarai I.M. Saleh tahun 1990-an untuk men-dapatkan FNGW ini.

\section{Pembahasan}

Tokoh yang mempublikasikan FNGW bukan saja I.M. Saleh melainkan juga Mahmud Hasan dan Syaifurrahman Salman. I.M. Saleh lebih dahulu mempublikasikan tulisannya dan Mahmud Hasan dan Syaifurrahman Salman mempublikasikan tulisannya (fotokopian) pada tahun 2006. Kedua versi itu hampir sama. Perbedaanya hanya bersifat redaksional, bukan esensial. Kalaupun ada penggunaan istilah yang berbeda, istilah itu mempunyai makna yang sama dengan istilah lain.

Menurut versi I.M. Saleh FNGW itu adalah sebagai berikut: (1) ma toâ đi Ruma lapo Rasu (yang taat kepada`Allah dan Rasul), (2) ma loa ro pade 'yang pandai dan cerdas (3) ma ntiri nggahi kalampa 'yang jujur dalam melaksanakan tugas' (4) ma poda nggahi paresa 'yang mampu menegakkan kebenaran' (5) ma mbani ro disa 'yang bertanggung jawab dan berani' (6) matenggo ro wale 'yang sehat jasmani dan rohani serta kuat' (7) mapisa ro guna 'berwibawa dan sakti', dan (8) londo dou taho 'keturunan orang baik-baik' .

Kedelapan ciri pemimpin tersebut mempunyai makna yang luas. Ciri pertama (ma toâ đi Ruma lapo rasu 'yang taat kepada Allah dan Rasul') mengandung makna bahwa pemimpin itu adalah seorang yang taat kepada Allah dan rasul-Nya. Pemimpin yang demikian disebut juga pemimpin beriman yang melihat keterbatasan dirinya sebagai makhluk. Apapun yang dilakukannya selalu kembali kepada pencipta (Allah) sebagai dzat yang mahatinggi. Penempatan diri sebagai makhluk yang diciptakan mengandung makna bahwa pemimpin itu adalah orang yang bertuhan. Hanya orang yang bertuhanlah yang dapat melakukan 
penghayatan keagamaan yang dalam atau menjadi orang yang religius. Pemimpin yang religius akan mampu melakukan komunikasi vertikal dengan pencipta dan komunikasi horizontal dengan sesama. Religiusitas seorang pemimpin akan memberikan warna khas dalam segala tindakannya.

Ciri percaya kepada Tuhan tidak dijumpai dalam teori sifat yang dikemukakan ahli-ahli kepemimpinan Barat, seperti E.E. Ghizeli dan Stogdil, L. Sank dan Robert J. Thierauf dkk dan lain-lain (lihat Suharto, 2001:39-51). Ciri pertama itu berkaitan dengan agama yang dianut oleh masyarakat Bima, yaitu Islam. Ciri itu merupakan identitas sebagai bangsa Timur yang bersifat teosentris. Ciri itu sekaligus membedakan dengan bangsa Barat yang bersifat antroposentris. Ciri pertama itu akan menjadi roh semua ciri yang lain.

Ciri kedua (maloa ro pade 'yang pandai dan cerdas') menggambarkan keluasan wawasan seorang pemimpin. Kata maloa dan pade mengandung arti yang hampir sama. Gabungan kedua kata itu mengandung makna 'berwawasan luas' atau 'berilmu' . Seorang pemimpin harus memiliki ilmu pengetahuan yang luas agar dapat menjawab semua tantangan yang dihadapi dalam memimpin umatnya. Wawasan yang luas akan menuntun pemimpin untuk memecahkan masalah dan membuat ramalan untuk melihat masa depan. Menurut Mahmud Hasan dan Saefurrahman Salman (2006:9) bahwa pemimpin yang memiliki ciri kedua adalah mereka yang mempunyai kapasitas intelektual dan kepekaan jiwa yang dalam sehingga mudah menanggapi berbagai masalah secara rasional, intuitif, dan tidak mudah emosional. Ilmu yang dimiliki dapat menjadi landasan berpikir sehingga seorang pemimpin lebih terbuka dalam menerima masukan dan kritikan. Ciri itu 
relevan dengan kemajuan ilmu dan teknologi yang menuntut semua orang untuk belajar.

Kehidupan modern adalah kehidupan yang dikuasai oleh ilmu dan teknologi. Oleh sebab itu, pemimpin modern harus menguasai ilmu dan teknologi. Persaingan dunia politik dan perdagangan, misalnya, pada saat sekarang tidak dapat dilepaskan dari ilmu dan teknologi. Produk-produk perdagangan seperti senjata, alat-alat kedokteran, pada hakikatnya adalah hasil ilmu dan teknologi. Penguasaan ilmu dan teknologi sangat penting bagi seorang pemimpin karena dapat menunjang kebijakan yang dibuat selama menjadi pemimpin.

Dua ciri di atas belum cukup untuk menjadikan seseorang pemimpin sehingga harus ditambah lagi dengan ciri ketiga (ma ntiri nggahi kalampa 'yang jujur dalam melaksanakan tugas') dan keempat (ma poda nggahi paresa 'yang mampu menegakkan kebenaran'), serta kelima (ma mbani ro disa 'yang bertanggung jawab dan berani'). Ciri ketiga dan keempat, serta kelima itu harus melekat pada setiap diri pemimpin. Kejujuran (ntiri nggahi) adalah kunci melakukan kerja sama dengan semua pihak. Orang lain akan mempercayai seorang pemimpin jika pemimpin itu jujur dalam berkata dan berbuat. Kejujuran adalah modal utama yang dapat menuntun perilaku pemimpin dalam menentukan kebijakan dan kerja sama dengan pihak lain.

Masalah kejujuran berkaitan erat dengan penegakan kebenaran. Penegakan kebenaran hanya dapat dilakukan oleh pemimpin yang jujur. Coba kita bayangkan kalau seorang pemimpin itu tidak jujur, yang terjadi adalah manipulasi yang menghalalkan semua cara. Akibatnya, nilai-nilai kebenaran terabaikan. Penegakan kebenaran itu berkaitan pula dengan penegakan hukum. Hukum adalah kunci menuju keadilan. Seorang pemimpin yang adil akan mampu mengendalikan diri untuk membuat 
garis batas antara kepentingan diri atau keluarganya dan kepentingan orang banyak.

Gabungan keempat ciri itu, dengan sendirinya akan "terjelma" menjadi ciri kelima (ma mbani ro disa 'yang bertanggung jawab dan berani'). Ciri kelima itu dapat dikatakan sebagai refleksi keempat ciri tadi. Kata mbani dan disa sebenarnya sama artinya, yaitu 'berani' dan mengandung konotasi 'menanggung risiko'. Sifat bertanggung jawab dan berani menghadapi risiko adalah sama nilainya dengan ungkapan edera nahu sura dou lapo dana "jangan saya asalkan untuk orang banyak" (Badrun, 2006:28). Ungkapan itu menggambarkan sifat seorang pemimpin yang mau berkorban untuk kepentingan masyarakatnya, bukan pemimpin yang memanfaatkan kesempatan untuk meraup keuntungan diri dan keluarganya. Ciri kelima itu menempatkan pemimpin BimaDompu sebagai seorang yang mengabdi kepada masyarakat. Pemimpin yang demikian tidak akan melakukan tindakan sewenang-wenang terhadap masyarakat, ia cenderung akan mengambil keputusan yang menyenangkan orang banyak. Keputusannya akan diwarnai perasaan kedamaian.

Seorang pemimpin haruslah sehat jasmani dan rohani (ciri keenam). Kata matenggo berati 'sehat pisik dan rohani' dan kata wale berarti 'kuat' yang berkonotasi 'ulet'. Gabungan kedua kata itu dapat berarti 'sehat dan ulet'. Orang yang sehat tentu memiliki kekuatan untuk melakukan berbagai kegiatan. Kuat saja belum cukup tetapi juga harus ulet.

Ciri ketujuh (mapisa ro guna 'berwibawa dan sakti') tidak dapat dipisahkan dari ciri yang lain. Sifat itu adalah refleksi dari sifat-sifat lain. Pemimpin yang beriman, berwawasan luas, jujur, cinta kebenaran (adil), dan bertanggung jawab akan menjadi sosok yang berwibawa. 
Kewibawaan adalah pancaran dari sifat baik yang bersumber dari dalam diri pemimpin. Pemimpin yang berwibawa dapat mengatasi segala masalah yang timbul dalam masyarakat. Perkataan dan perbuatannya akan didengar dan menjadi contoh bagi orang banyak. Pemimpin yang berwibawa akan mudah berkomunikasi dengan semua pihak.

Ciri terakhir adalah londo dou taho 'keturunan orang baik-baik'. Ciri itu berkaitan dengan pandangan bahwa dari keturunan atau keluarga baik-baiklah akan lahir pemimpin yang baik. Tanpa mengabaikan faktor lingkungan, masyarakat Bima-Dompu cenderung menempatkan faktor heriditas sebagai faktor yang 'penting'. Istilah londo dou taho pada hakikatnya berkonotasi 'bermoral baik'. Makna istilah itu lebih mengarah pada nilai positif. Seorang pemimpin yang bermoral baik, akan membawa masyarakat yang dipimpinnya ke arah berpikir dan berbuat baik, bukan mengajak untuk memanipulasi dan menipu orang lain untuk mempertahankan kekuasaan.

Dalam kehidupan modern ini, moral sangat diperlukan karena hal itu adalah kendali utama segala perilaku kita. Orang yang tidak memiliki moral baik, ia akan terjerumus dalam permainan tanpa nilai (kebenaran). Kehidupan tanpa nilai adalah anarkis karena orang dapat berbuat apa saja sesuai dengan keinginannya. Pemimpin yang bermoral baik adalah yang dapat dipercaya oleh orang yang dipimpinnya. Ia tidak akan berbuat serakah dan sombong dalam menjalankan misinya sebagai pemimpin.

Pemimpin yang bermoral baik akan melahirkan keputusan yang diwarnai oleh emosi kedamaian, penerimaan, dan keberanian (Confido, 2008:19). Semua keputusan yang diambilnya dipikirkan secara matang sehingga untung dan ruginya selalu dipertimbangkan. Pemimpin seperti itulah yang mampu membangun masyarakat dengan penuh tanggung jawab. 
Kedelapan ciri pemimpin yang telah diuraikan di atas, merupakan satu kesatuan yang satu sama lain tidak dapat dipisahkan. Kalau segi delapan digelindingkan seperti sebuah roda, ia dapat bergerak dengan lancar, tanpa hambatan. Gerak itu akan berawal dari satu sudut menuju sudut lain. Kalau roda itu diputar dengan cepat, sudut-sudut itu tidak tampak lagi, yang tampak hanyalah sebuah lingkaran. Artinya, ciri itu telah menyatu, ibaratkan sebuah bangunan yang dilihat dari kacamata ilmu jiwa Gestalt. Menurut pandangan kaum Gestalt, seperti dikatakan Ehrenfels bahwa dalam kesadaran manusia terlebih dahulu muncul satu gambaran totalitas, baru muncul bagian-bagian yang membentuk totalitas tadi (dalam Kartono, 1996:160-161). Gambaran seperti itulah yang terlihat jika kedelapan unsur FNGW menyatu. Kualitas seorang pemimpin merupakan perpaduan 8 unsur FNGW tersebut. Oleh sebab itu, kedelapan unsur itu tidak dilihat secara parsial.

Meskipun FNGW adalah hasil budaya lisan, nilainya tidak kalah dengan hasil pemikiran para ahli kepemimpinan modern. FNGW dapat digolongkan dalam teori kepemimpinan sifat yang berkembang pada tahun 1940-an. Teori Sifat menekankan pada atribut-atribut pribadi dari seorang pemimpin. Teori ini didasarkan pada asumsi bahwa beberapa orang merupakan pemimpin alamiah yang dianugerahi ciri yang tidak dimiliki oleh orang-orang yang bukan pemimpim, seperti intuisi yang dalam, pandangan masa depan, dan kekuatan persuasif. Kekuatan itulah yang membuat keberhasilan manajerial seorang pemimpin (2006:11).

Teori sifat tergolong teori tertua. Orientasi teori pada sifat pribadi membuat teori itu masih relevan dengan teori lain seperti teori perilaku, teori kepemimpinan situasional, teori atribusi, teori karismatik, transaksional dan transformatif. Saya katakan demikian karena sifat pribadi tetap melekat setiap pemimpin yang menggunakan teori dan gaya 
apapun. Teori terbaru lebih banyak berorientasi manajerial dan memperhatikan unsur yang dipimpin, misalnya teori transaksi (dalam Rivai, 2006:15), yang mengandung dua aspek (1) memotivasi pengikut mereka ke arah pemahaman tujuan dan tuntutan tugas, dan (2) pemberian pertimbangan dan rangsangan intelektual yang diindividualkan dan memiliki kharisma.

Ciri kepemimpinan FNGW, walaupun bersifat tradisional, nilainya sama dengan nilai kehidupan modern yang bersifat demokratis. Percaya kepada Tuhan, berwawasan luas, jujur, berani menanggung risiko, sehat jasmani dan rohani, berwibawa, dan bermoral baik adalah sifat yang harus dimiliki oleh manusia modern, baik yang menjadi pemimpin maupun tidak. Nilai yang terkandung dalam FNGW harus dipahami dalam pengertian yang luas dan fleksibel. Hanya dengan cara seperti itu nilai yang terkandung dalam FNGW dapat diapresiasi.

Setelah membahas relevansi FNGW dengan ciri kepemimpinan modern, berikut saya akan mengapa FNGW tidak populer dalam masyarakat etnik Bima. Untuk menjawab pertanyaan itu sebaiknya kita melihat apresiasi masyarakat etnik Bima atas tradisi lisannya.

Kalau dicermati, tradisi lisan yang hidup dalam masyarakat etnik Bima jumlahnya terbatas, misalnya pertunjukan patu, pelamaran, perkawinan, dan pencukuran (bayi). Pertunjukan patu adalah jenis tradisi lisan yang paling digemari. Kegemaran itu disebabkan sifat pertunjukan patu yang mampu menjadi ajang ekspresi budaya dan diri pematu dan penonton.

Dalam masyarakat etnik Bima, tradisi pelamaran, perkawinan, dan pencukuran (bayi) dengan segala ritualnya masih dipertahankan, walaupun sudah dimodifikasi. Salah satu jenis tradisi lisan lagi yang cukup maju adalah pertenunan. Jenis tradisi lisan yang lainnya sudah 
tidak tampak lagi. Fenomena itu ada hubungannya dengan sikap masyarakat etnik Bima yang cenderung berorientasi praktis. Hal itu dapat dibuktikan dengan tidak adanya revitalisasi adat atau cabang kesenian tradisional.

Masalah revitalisasi adat atau cabang kesenian tradisional perlu diperhatikan karena dapat menjadi daya tarik suatu daerah. Daya tarik yang bersumber dari tradisi lisan akan lebih menarik jika dibandingkan dengan daya tarik yang dibuat baru karena tradisi adalah akar sebuah masyarakat. Jika kita ingin memahami suatu masyarakat, sebaiknya kita melihat tradisinya. Lagi pula, kehidupan suatu masyarakat tidak cukup hanya dengan mencari nafkah atau melakukan kegiatan rutin lainnya, tetapi juga harus dibarengi dengan kegiatan yang membangun kesadaran kolektif etnik dan inilah yang menjadi wilayah tradisi lisan.

Tidak kenalnya masyarakat etnik Bima atas FNGW adalah kekeliriuan besar yang dilakukan generasi sebelumnya. Seandainya generasi sebelumnya tanggap akan penting-nya makna FNGW, sudah selayaknya diperkenalkan pada generasi sekarang melalui pelajaran muatan lokal. Memang ada sebuah bangunan yang melambangkan FNGW, yaitu yang terletak di pintu masuk istana Bima. Tetapi, apalah arti sebuah bangunan, jika tidak diberi penjelasan. Sebuah bangunan akan bermakna sebagai lambang identitas, kalau penjelasan verbalnya disertakan. Penjelasan verbal itulah yang perlu dibuat dan disosialisasikan.

Belum terlambat bagi masyarakat etnik Bima untuk merevitalisasi FNGW. Generasi muda sebagai ahli waris tradisi lisan (FNGW) berhak mengetahui khazanah budayanya. Untuk itu diperlukan sikap arif dari generasi tua untuk meneruskan tradisi itu kepada generasi sekarang. 
Mabasan - Vol. 2 No. 1 Januari-Juni 2008

Tentu saja, tersosialisasinya filsafat itu harus dilandasi oleh kesadaran bersama untuk memelihara tradisi lisan.

\section{Simpulan}

FNGW adalah warisan tradisi lisan yang mempunyai nilai yang relevan dengan ciri kepemimpinan modern. Relevansi itu harus dilihat dalam makna yang luas. Ciri pertama pada dasarnya adalah sama dengan kepercayaan atau percaya pada Tuhan; ciri kedua adalah sama dengan berwawasan luas; ciri ketiga adalah sama dengan kejujuran; ciri keempat adalah sama dengan adil atau keadilan; ciri kelima adalah sama dengan berani menanggung risiko; ciri keenan adalah sama dengan sehat jasmani dan rohani; ciri ketujuh adalah sama dengan berwibawa atau berpengaruh; ciri kedelapan adalah sama dengan bermoral baik. Kedelapan ciri itu sejajar dengan pemikiran ahli kepemimpinan sifat dan relevan dengan nilai kehidupan modern yang kita jalani sekarang.

Filsafat itu terlupakan oleh masyarakat etnik Bima karena tidak adanya kesadaran apresiatif masyarakat, khususnya genarasi tua atas tradisi lisan. Hal itu disebabkan terlalu praktisnya cara berpikir masyarakat etnik Bima. Untuk itu, mulai saat sekarang masyarakat etnik Bima perlu menggali kembali FNGW agar identitas itu dapat diteruskan kepada generasi selanjutnya. 


\section{Daftar Pustaka}

Badrun, Ahmad. 2006. Struktur dan Makna Ungkapan Tradisional BimaDompu. Mataram: Mataram Universiy Press.

Confido, Jemy V., 2008. "9 Jenis Emosi dalam Pengambilan Keputusan Sehari-hari”. Dalam Lionmag. Mei 2008.

Goody, Jack. "Oral Culture". Dalam Richard Bauman. 1992. Folklore, Cultural Perfor-mance, and Popular Enterteinment. New York: Oxford University Press.

Kartono, Kartini. 1996. Psikologi Umum. Bandung: Mandar Maju.

Mahmud Hasan, Abdul Malik dan Syaifurrahman Salman. 2006. "Nggusu Waru: Kriteria Pemimpin menurut Budaya Lokal Mbojo (Dompu-Bima)". Dompu: Yayasan Nuansa Nusa.

Saleh, I.M. 1985. “Sekitar Kerajaan Dompu”. Pemda Kabupaten Dompu.

Sutarto. 2001. Dasar-dasar Kepemimpinan Administrasi. Yogyakarta: Gadjah Mada University Press.

Rifai, Veithzal. 2006. Kepemimpinan dan Perilaku Organisasi. Jakarta: Raja Grafindo Persada. 